\title{
NANOEMULSIFICATION - A NOVEL TARGETED DRUG DELIVERY TOOL
}

\author{
SL Hari Ku mar, *Vishal Singh \\ Ray at \& Bahra Institute of Pharmacy, Sahauran, Kharar, Mohali(Pb), 140104 \\ *Corresponding Author's Email: slharikumar@gmail.com, Phone: 9888017546
}

Received 05 May 2012; Review Completed 18 May 2012; Accepted 27 June 2012, Available online 15 July 2012

\begin{abstract}
Nanoemulsions have the potential in Pharmaceutical industries because of the transparency at high droplet volume fraction, higher rate of bioavavilability or diffusion and increased shlf life of the pharmaceuticals. Nanoemulsion as a part of multiphase colloidal dispersion, is a heterogeneous system composed of fine oil in water or water in oil dispersion with surfactant and cosurfactant having droplets covering the size range of 20-600 nm and show narrow size distribution. These are prepared usinh high energy emulsification method including microfluidic ans ultrasonic methods, which rupture large micro droplets into nanoscale droplets provides useful non equilibrium system of structured liquids. Different oil in water $(\mathrm{o} / \mathrm{w})$ or water in oil (w/o) nanoemulsions was prepared by aqueous phase titration method. Nanoemulsion were characterized by thermodynamic stability tests for phase separation, creaming, cracking, coalescence or phase inversion and prepared nanoemulsion formulations were characterized by specifying molecular constituents, quantity of these constituents and the sizes of the droplet structure following the formation of emulsion by shear. It can be evaluated for their morphology, droplets size, viscosity, pH, optical clarity, zeta potential, conductivity, transmission electron microscopy, polydispersity. Pharmaceutical application of nanoemulsion formulation was controlled drug delivery, target drug delivery, nutraceuticals, food products, transdermal and colloidal drug delivery. This review includes the preparation, characteristics, evaluation and application of nanoemulsion as a drug delivery tool.

Keywords: High energy emulsification, Jet dispersers, Microfluidizer, Nanoemulsion, Ultrasonication, Targeted drug delivery, Nanotechnology.
\end{abstract}

\section{INTRODUCTION}

An emulsion is a system in which one fluid is dispersed in another with which it is immiscible. Separation of the phases is prevented by the addition of a suitable surfactant. In the vast majority of emulsion research, one of the liquid phase is water.

The term "Nanoemulsion" refers to a thermodynamically stable isotropically clear dispersion of two immiscible liquids, such as oil and water, stabilized by an interfacial film of surfactant molecules. A nanoemulsion is considered to be a thermodynamically or kinetically stable liquid dispersion of an oil phase and a water phase, in combination with a surfactant. The dispersed phase typically comprises small particles or droplets, with a size range of $5 \mathrm{~nm}-200 \mathrm{~nm}$, and has very low oil/water interfacial tension. Because the droplet size is less than
$25 \%$ of the wavelength of visible light, nanoemulsion are transparent. These are formed readily and sometimes spontaneously, generally without high-energy input. In many cases a co surfactant or co solvent is used in addition to the surfactant, the oil phase and the water phase.

Three types of Nanoemulsion are most likely to be formed depending on the composition:

Oil in water Nanoemulsion wherein oil droplets are dispersed in the continuous aqueous phase

Water in oil Nanoemulsion wherein water droplets are dispersed in the continuous oil phase;

Bi-continuous Nanoemulsion where in microdomains of oil and water are inter-d is persed within the system.

Table 1: Differences between emulsion and nanoemulsion

\begin{tabular}{|l|l|l|}
\hline Emulsion & Nanoemulsion & Microemulsion \\
\hline Excellent kinetic stability. & Kinetically unstable. & They posses some kinetic stability \\
\hline $\begin{array}{l}\text { Thermodynamically unstable and will } \\
\text { eventually phase separate. }\end{array}$ & $\begin{array}{l}\text { Thermodynamically stable and no phase } \\
\text { separation occur. }\end{array}$ & Thermodynamically stable \\
\hline Emulsions appear cloudy. & Nanoemulsions are clear or translucent. & Microemulsion are clear \\
\hline $\begin{array}{l}\text { Methods involved in preparation of } \\
\text { emulsion require a large input of energy. }\end{array}$ & $\begin{array}{l}\text { Methods of preparation do not require } \\
\text { energy input. }\end{array}$ & $\begin{array}{l}\text { Methods of preparation do not } \\
\text { require energy input. }\end{array}$ \\
\hline
\end{tabular}

Nanoemulsion is colloidal dispersions composed of an oil phase, aqueous phase, surfactant and co surfactant at appropriate ratios. Unlike coarse emulsions micronized with external energy, nanoemulsion is based on low interfacial tension which is achieved by adding a co surfactant, which leads to spontaneous formation of a thermodynamically stable nanoemulsion. The droplet size in the dispersed phase is very small, usually below $140 \mathrm{~nm}$ in diameter, which makes the nanoemulsion transparent liquids. ${ }^{2}$

In principle, nanoemulsion can be used to deliver drugs to the patients via several routes, but the topical application of nanoemulsion has gained increasing interest. The three main factors determining the transdermal permeation of 
drugs are the mobility of drug in the vehicle, release of drug from the vehicle, and permeation of drug into the skin. These factors affect either the thermodynamic activity that drives the drug into the skin or the permeability of drug in the skin, particularly stratum corneum. Nanoemulsion improve the transdermal delivery of several drugs over the conventional topical preparations such as emulsions ${ }^{3,4}$ and gels ${ }^{5,6}$.

Mobility of drugs in nanoemulsion is more facile $e^{4,6,7}$, as compared to the with gel former which will increase its viscosity and further decrease the permeation in the skin. ${ }^{5}$ The superior transdermal flu $x$ from nanoemu lsion has been shown to be mainly due to their high solubilization potential for lipophilic and hydrophilic drugs. This generates an increased thermodynamic activity towards the skin. ${ }^{4,7,8}$ Nanoemulsion may affect the permeability of drug in the skin. In this case, the components of nanoemulsion serve as permeation enhancers.

Several compounds used in nanoemulsion have been reported to improve the transdermal permeation by altering the structure of the stratum corneum. For example, short chain alkanols are widely used as permeation enhancers. ${ }^{9,10,11}$ It is known that oleic acid, a fatty acid with one double bond in the chain structure, perturbs the lipid barrier in the stratum corneum by forming separate domains which interfere with the continuity of the multilamellar stratum corneum and may induce highly permeable pathways in the stratum corneum. ${ }^{12,13,14}$ Isopropyl myristate (IPM) is used as a permeation enhancer in transdermal formulations, but the mechanism of its action is poorly understood. ${ }^{15}$ Non-ionic surfactants are widely used in topical formulations as solubilising agents but some recent results indicate that they may affect also the skin barrier function. ${ }^{16}$ It is of interest to explore the effects of these components in the organized nanoemulsion structures.

A unique attempt was made ${ }^{17}$ to emulsify coconut oil with the help of polyoxyethylene 2-cetyl ether (Brij 52) and isopropanol or ethanol, forming stable is otropic dispersion thus paving way for use of plant and vegetable oil to be used as oil phase in nanoemulsion.

A combination of surfactants, particularly ionic and nonionic, can be very effective at increasing the extent of the nanoemulsion region. Examples of non-ionic include polyoxyethylene surfactants such as Brij 35 (C12E35) or sugar esters such as sorbitan monooleate (Span 80). Phospholipids are a notable example of zwitterionic surfactants and exhibit excellent biocompatibility. Lecithin preparations from a variety of sources including soybean and egg are available commercially and contain diacylphosphatidylcholine as its major constituent. ${ }^{18-21}$ Quaternary ammonium alkyl salts form one of the best known classes of cationic surfactants, with hexadecyltrimethyl ammonium bromide (CTAB) and the twin-tailed surfactant didodcecylammonium bromide (DDAB) are amongst the most well known (Olla et al., 1999). The most widely studied anionic surfactant is probably sodium bis-2-ethylhexylsulphosuccinate (AOT) which is twin-tailed and is a particularly effective stabiliser of w/o microemulsions. ${ }^{22}$

\section{ADVANTAGES OF NANOEMULSION}

- Nanoemulsion is the approach to improve water solubility and ultimate bioavailability of lipophilic drugs. The nano-sized droplets leading to enormous interfacial areas associated with nanoemulsions would influence the transport properties of the drug, an important factor in sustained and targeted drug delivery $^{38}$.

- Nanoemulsions have been reported to make the plasma concentration profiles and bioavailability of drugs more reproducible ${ }^{38-39}$.

- Fine oil droplets empty rapidly from the stomach and promote wide distribution of the drug throughout the intestinal tract and thereby minimizing irritation frequently encountered with extended contact of the drug and gut wall ${ }^{40}$.

- Higher solubilization capacity than simple micellar solutions and their thermodynamic stability offers advantages over unstable dispersions such as emulsions and suspensions because they can be manufactured with little energy input (heat or mixing) and have a long shelf life ${ }^{41}$.

- They also provide ultra low interfacial tension and large $\mathrm{o} / \mathrm{w}$ interfacial areas ${ }^{41}$.

- They also offer an advantage over existing self emulsifying system in terms of rapid onset of action (no extra time for dispersion) and reduced intersubject variability in terms of GIT fluid volume.

- They possess high kinetic stability and optical transparency resembling to microemulsions ${ }^{42}$.

- The structures in the nanoemulsions are much smaller than the visible wavelength, so most nanoemulsions appear optically transparent, even at large loading ${ }^{42}$.

- They have potential to deliver peptides that are prone to enzymatic hydrolysis in GIT ${ }^{43}$.

- Nanoemulsions have higher surface area and higher free energy than macro emulsions that make them an effective trans port system. ${ }^{44}$

- Problems of inherent creaming, flocculation, coalescence, and sedimentation are not seen in nanoemulsions, which are commonly associated with macroemulsions. ${ }^{45}$

- Nanoemulsions can be formulated in numerous dosage foam such as creams, liquids, sprays and foams. ${ }^{46}$

- It is non-toxic and non-irritant so can be easily applied to skin and mucous membranes.

- Nanoemulsions is formulated with surfactants, which are approved for human consumption (GRAS) so they can be taken by enteric route. ${ }^{47}$

- It is do not damage healthy human and animal cells, so nanoemulsions are suitable for human and veterinary therapeutic purposes ${ }^{48}$.

\section{DISADVANTAGES OF NANO EMULSION}

- The formulation of nanoemulsions is an expensive process due to size reduction of droplets is very difficult as it required a special kind of instruments and process methods. For example, homogenizer (instrument required for the nanoemulsions formulation) arrangement is an expensive process. More ever microfluidization and ultrasonication (manufacturing process) require large amount of financial support. 
- The stability of nanoemulsions is quite unacceptable and produces a big problem during the storage of formulation for the longer time. Ostwald ripening is the main problem associated with unacceptability of nanoemulsions formulations. Ostwald ripening is due to the high rate of curvature of small droplet show greater solubility as compared to large drop with a low radius of curvature ${ }^{49-50}$.

\section{PREPARATION OF NANOEMULS ION}

The drug is to be dissolved in the lipophilic part of the nanoemulsion i.e. oil and the water phases can be combined with surfactant and a cosurfactant is then added at slow rate with gradual stirring until the system is transparent. The amount of surfactant and cosurfactant to be added and the percent of oil phase that can be incorporated shall be determined with the help of pseudoternary phase diagram. Ultrasonicator can finally be used so to achieve the desired size range for dispersed globules. It is then being allowed to equilibrate. Gel may be prepared by adding a gelling agent to the above. Carbo mers (crosslinked polyacrylic acid polymers) are the most widely used gelling agent.

\section{Factors to be considered during preparation of nanoemulsion}

Three important conditions:

- Surfactants must be carefully chosen so that an ultra low interfacial tension $(<10-3 \mathrm{mN} / \mathrm{m})$ can be attained at the oil / water interface which is a prime requirement to produce nanoemulsions.

- Concentration of surfactant must be high enough to provide the number of surfactant molecules needed to stabilize the nano droplets to be produced by an ultra low interfacial tension.

- The interface must be flexible or fluid enough to promote the formation of nanoemulsions.

Nanoemulsion, being non-equilibrium systems cannot be formed spontaneously. Consequently, energy input generally from mechanical devices or from the chemical potential of the components is required, Nanoemulsion formation by the so called dispersion or high energy emulsification method is generally achieved using high shear stirring, high pressure homogenizers and ultrasound generators. It has been shown that the apparatus supplying the available energy in the shortest time and having the most homogeneous flow produces the smaller sizes. High pressure homogenizers meet these requirements; therefore, they are the most widely used emulsifying machines to prepare nanoemulsion. Generally, the conventional high pressure homogenizers work in a range of pressures between 50 and $100 \mathrm{Mpa}$. Pressure as high as 350Mpa have been achieved in a recently developed instrument. Ultrasonication emulsification is also very efficient in reducing droplet size but it is appropriate for small batches. On the preparation of polymerizable nanoemulsion has shown that the efficiency of dispersion process is strongly dependent on ultrasonication time at different amplitudes and that the more hydrophobic the monomer is the longer the sonication time required ${ }^{39}$.

\section{METHODS OF PREPARATION OF NANOEMULSION}

\section{Phase inversion method}

Fine dispersion is obtained by chemical energy resulting of phase transitions occur through emulsification method. The adequate phase transitions are produced by changing the composition at constant temperature or by changing the temperature at constant composition, Phase inversion temperature (PIT) method was introduced by Shinoda et al. based on principle of the changes of solubility of polyoxyethylene- type surfactant with temperature. This surfactant becomes lipophilic as increase in temperature because of dehydration of polymer chain. At low temperature, the surfactant monolayer has a great positive spontaneous curvature forming oil swollen micellar solution phase $\mathrm{e}^{33}$.

Table 2: List of oils, surfactants and cosurfactants used for preparation of nanoemulsion

\begin{tabular}{|c|c|c|}
\hline Oil (Chemical Name) & Surfactant & Cosurfactant \\
\hline $\begin{array}{l}\text { Captex } \\
\text { Tricaory late/Caprate), } \\
\text { Captex 200 (Glyceryl } \\
\text { Dicapry late/Dicaprate Glycol), } \\
\text { Captex } 8000 \text { (Glyceryl Tricaprylate ), } \\
\text { Witepsol (90:10\% w/w c12 Glyceride tri: } \\
\text { diesters), } \\
\text { Myritol 318 (c8/c } 10 \text { triglycerides), } \\
\text { 1sopropyel myristate (Myristic acid } \\
\text { isopropyl ester). }\end{array}$ & $\begin{array}{l}\text { Capryol 90; } \\
\text { Gelucire 44/14, 50/13; } \\
\text { Cremophor RH 40; } \\
\text { Imwitor 191, 308(1), 380, 742, } 780 \mathrm{~K}, 928 \text {, } \\
\text { 988; } \\
\text { Labrafil M } 1944 \mathrm{CS}, \mathrm{M} 2125 \mathrm{CS} ; \\
\text { Lauroglycol 90; } \\
\text { PEG MW > 4000; } \\
\text { Plurol Ole ique CC 497; } \\
\text { Polo xamer } 124 \text { and } 188 ; \\
\text { Softigen } 701,767 ; \\
\text { Tagat TO; } \\
\text { Tween } 80 .\end{array}$ & $\begin{array}{l}\text { TranscutolP; } \\
\text { Glycerin; Ethylene glycol; } \\
\text { Propylene glycol; } \\
\text { Ethanol; } \\
\text { Propanol. }\end{array}$ \\
\hline
\end{tabular}

\section{Sonication method}

Sonication method is best way to prepare nanoemulsions. In this method the droplet size of conventional emulsion or microemulsions were reduced with the help of sonication mechanism. This method is not applicable for large batches, but only small batches of nanoemulsions can be prepared by this method ${ }^{34}$.

\section{Ul trasonic System}




\section{Singh et al}

Journal of Drug Deli very

In ultrasonic emulsification, the energy input is provided through so called sonotrodes (sonicator probe) containing piezoelectric quartz crystals that can be expand \& contract in response to alternating electrical voltage. As the tip of sonicator probe contacts the liquid, it generates mechanical vibration and therefore cavitations occurs, which is the main phenomenon responsible for ultrasonically induced effects. Cavitation is the formation and collapse of vapour cavities in a flowing liquid.. Such a vapour cavity forms when the local pressure is reduced to that of at the temperature of the flowing liquid because of local velocity changes. The collapse of these cavities causes powerful shock waves to radiate throughout the solution in proximity to the radiating face of the tip, thereby breaking the dispersed droplets. Within the ultrasound range, the power available varies inversely with the frequency and only powerful ultrasound $(0-200 \mathrm{kHz})$ is able to produce physical and chemical changes such as emulsification.

Ultrasound can be used directly to produce emulsion, but since breaking an interface requires a large amount of energy, it is better to prepare coarse emulsion before applying acoustic power. Due to small product throughput the ultrasound emulsification process mainly applied in laboratories where emulsion droplet size as low as 0.2 micro meter can be obtained ${ }^{35}$.

\section{Micr oflui dizer}

It is possible to produce emulsion at much higher pressures up to approximately $700 \mathrm{Mpa}$, in the nozzle of microfludizer that is the heart of this device (the interaction chamber), two jets of crude emulsion from two opposite channels collide with one another. The process stream is delivered by a pneumatically powered pump that is capable of pressurizing the in-house compressed air (150-650 Mpa) up to about $150 \mathrm{Mpa}$. Forcing the flow stream by high pressure through microchannels toward an impingement area creates a tremendous shearing action, which can provide an exceptionally fine emulsion ${ }^{36}$.

\section{Jet Disperser}

Forcing the flow stream by high pressure through microchannels towards an impregnated area creates a
\& Therapeutics; 2012, 2(4), 40-45

tremendous shearing action, which can provide an exceptionally fine emulsion. In general, initial forces in turbulent flow along with cavitations are predominantly responsible for droplet disruption in microfluidizer. Disruption in laminar elongational flow is also possible, especially when emulsion has high viscosity.

In the jet disperser two or more jets of crude emulsion each from opposing bores collide with one another but at a different design than microfludizer, the diameter of the bores injet dispersers are typically $0.3-0.5 \mathrm{~mm}$. Finally an "orifice plate" is the simplest construction form for a homogenizing nozzle. The diameter of orifice bore is of same order of magnitude as the jet dispersers and inlet head diameter of orifice plate is typically $10-60 \mathrm{~nm}$, in jet dispersers \& orifice plates, droplets are disrupted predominantly due to laminar elongational flow ahead of the bores. Unlike radial diffusers, the nozzle is microfluidizers; jet dispersers and orifice plate contain no moving parts, so they can be used at high pressures up to 300-400 $\mathrm{Mpa}^{37}$.

\section{PHYS ICOCHEMICAL CHARACTERIZATION OF NANOEMULS IONS}

\author{
Particle Size Analysis. \\ Rheological Measurements. \\ Refractive Index. \\ Surface Tension. $p H$ and Osmotic Pressure. \\ PATENTS RELATED TO NANOEMULSION
}

Patents are the strongest form of intellectual property protection and are essential to the growth of a nanotechnology company. Similar to their importance to the development of the biotechnology and informational technology industries, patents will also play a critical role in the success of the global nanotechnology revolution; in fact patents are already shaping the nascent and rapidly evolving field of nanoscience and small technologies. As companies develop the products and processes of nantechnology, and begin to seek commercial applications for their inventions, securing valid and defensible patent protection will be vital to their long term survival.

Table 3: List of patents related to nanoemulsion

\begin{tabular}{|l|l|l|}
\hline Patent Application Title & Patent App No. & Date \\
\hline Topical compositions and methods of detection and treatment & 20120039814 & $2012 / 02 / 16$ \\
\hline Cancer vaccine compositions and methods of using the same & 20110280911 & $2011 / 11 / 17$ \\
\hline Methods of using nanoemulsion compositions having anti- inflammatory activity & 20110200657 & $2011 / 08 / 18$ \\
\hline Stable nanoemulsions for ultrasound-mediated of drug delivery and imaging & 20110177005 & $2011 / 07 / 21$ \\
\hline Method for the preparation of nanoparticles from nanoemulsion & 20110135734 & $2011 / 06 / 09$ \\
\hline Nanoemulsion formulations for direct delivery & 20110045050 & $2011 / 02 / 24$ \\
\hline Lyophilized nanoemulsion & 20110015266 & $2011 / 01 / 20$ \\
\hline Antimicrobial nanoemu lsion compositions and methods & 20110070306 & $2011 / 03 / 24$ \\
\hline Nanoemulsion vaccines & 20100316673 & $2010 / 12 / 16$ \\
\hline $\begin{array}{l}\text { Perfluorocarbon nanoemulsion containing quantum dot nanoparticles and method for } \\
\text { preparing the same }\end{array}$ & 20100233094 & $2010 / 09 / 16$ \\
\hline $\begin{array}{l}\text { Nanoemulsion of resveratrol-phospholipid complex and method for preparing the } \\
\text { same and applications thereof }\end{array}$ & 20100297199 \\
\hline $\begin{array}{l}\text { Compositions for treatment and prevention of acne, methods for making the } \\
\text { compositions, and methods of use thereof }\end{array}$ & 20100226983 \\
\hline Stable mixed emulsions & $2010 / 11 / 25$ \\
\hline $\begin{array}{l}\text { Oil-in-water nanoemulsion, a cosmetic composition and a cosmetic product } \\
\text { comprising it, a process for preparing said nanoemulsion }\end{array}$ & 20090208541 \\
\hline
\end{tabular}




\section{APPLICATIONS OF NANOEMULSION}

Nanoemulsions containing pharmaceutically active agents can be utilized for the production of pharmaceutical preparations, the nanoemulsion being mixed, as the active component, with a solid or liquid vehicle suitable for therapeutic administration. If desired, a special galenic form can be imparted to the mixture. The following galenic forms of administration can be considered, in this connection: Ampoules, especially sterile injection and infusion solutions; solutions, especially oral liquids, eye drops and nose drops which can contain various auxiliary substances in addition to the nanoemulsion; aerosols without metering feature, and dosing aerosols, which can contain propellant gas and stabilizers besides the nanoemulsion; hydrophilic and hydrophobic gels and ointments containing the nanoemulsion; o/w or w/o creams containing the nanoemulsion; lotions and pastes containing the nanoemulsion.

\section{Ocular Deli very}

Oil in water emulsions are being explored for improved topical lipophilic drug delivery to the eye. Lipophilic drug loaded o/w ocular emulsions provide equivocally a better balance between ocular bioavailability improvement and patient comfort following topical instillation into the eye e.g. Piroxicam, pilocarpine, indomethacin, cyclosporine $\mathrm{A}^{56}$.

\section{Percutaneous Route}

Many drugs exhibit low skin penetration, which results in poor efficacy. As opposed to common chemical skin penetration enhancers, organic solvents, which are generally associated to some degree with skin irritation, toxicity and sensitization, a solvent free topical vehicle based on drug entrapment in the o/w emulsion droplets of submicron size is more efficacious in terms of percutaneous absorption with possibly devoid of adverse effects. In addition, the uniqueness of the large internal hydrophobic core of o/w submicronized emulsion droplets allows high solubilization capacity for water insoluble topically active medicaments and also aids in carrying water, an excellent softener, to the skin e.g. NSAIDs, diazepam, $\alpha$-tocopherol, antifungal drugs (econazole or miconazole nitrate), EMLA (Eutectic mixtures of local anaesthetic) has proven to be a useful medication for children. It is an emulsion containing a mixture of lidocaine and prilocaine. This cream gives an effective deep sedation ${ }^{56}$.

\section{Nasal Route}

The nasal route has received great attention due to number of advantages over parenteral and oral administration especially by-passing the liver. Nanoemulsions increase absorption by solubilizing the drug in the inner phase of an emulsion and prolonging contact time between emulsion droplets and nasal mucosa e.g. a lipid soluble rennininhibitor was incorporated into an o/w emulsion. Enhanced and prolonged in vivo nasal absorption was observed in emulsion compared to aqueous suspension. Other drugs which have been formulated for nasal delivery are insulin and tes tosterone ${ }^{56,57}$.

\section{Use of Nanoemulsion in Cosmetics}

Nanoemulsions have recently become increasingly important as potential vehicles for the controlled delivery of cosmetics and for the optimized dispersion of active ingredients in particular skin layers.

Due to their lipohilic interior, nanoemulsions are more suitable for the transport of lipophilic compounds than liposomes. Similar to liposomes, they support the skin penetration of active ingredients and thus increase their concentration in the skin. Another advantage is the smallsized droplet with its high surface area allowing effective transport of the active to the skin. Furthermore, nanoemulsions gain increasing interest due to their own bioactive effects. This may reduce the trans-epidermal water loss (TEWL), indicating that the barrier function of the skin is strengthened. Nanoemulsions are acceptable in cosmetics because there is no inherent creaming, sedimentation, flocculation or coalescence observed within macroemulsions. The incorporation of potentially irritating surfactants can often be avoided by using high-energy equipment during manufacturing ${ }^{58}$.

\section{Antimicrobial Nanoemulsions}

Antimicrobial nanoemulsions are oil-in-water droplets that range from 200-600 $\mathrm{nm}$. They are composed of oil and water and are stabilized by surfactants and alcohol. The nanoemulsion has a broad spectrum activity against bacteria (e.g., E. coli, Salmonella, S. aureus), enveloped viruses (e.g., HIV, Herpes simplex), fungi (e.g., Candida, Dermatophytes), and spores (e.g., anthrax). The nanoemulsion particles are thermodynamically driven to fuse with lipid-containing organisms. This fusion is enhanced by the electrostatic attraction between the cationic charge of the emulsion and the anionic charge on the pathogen. When enough nanoparticles fuse with the pathogens, they release part of the energy trapped within the emulsion. Both the active ingredient and the energy released destabilize the pathogen lipid membrane, resulting in cell lysis and death ${ }^{59}$.

\section{CONCLUS ION}

Although high energy emulsification method is traditionally used for the preparation of nanoemulsion formulation but low emulsion emulsification method now create an attraction due to their wide application and advantages as a formulation and stability aspects. The applications of nanoemulsion are limited by the instability. Stability of formulation may be enhanced by controlling various factors such as type and concentration of surfactant and co surfactant, type of oil phase, methods used, process variables and addition of additives used over the inter phases of nanoemulsion formulation. Overall nanoemulsion formulation may be considered as effective, safe and patient compliance formulation for the delivery of pharmaceuticals and in cosmetic science after controlling the instability factors.

\section{ACKNOWLEDGEMENTS :}

The authors thankful to Rayat \& Bahra Institute of Pharmacy, Mohali for extended support for the research. 


\section{REFERENCES}

1. Shinoda K, Lindman B, Organised surfact ant systems: microemulsions, Langmuir; 1987, 3, P. 135-149.

2. Tenjarla SN, Microemulsions: An overview and pharmaceutical applications, Critical Reviews TM in Therapeutic Drug Carrier Systems; 1999, 16, 461-521.

3. Ktistis G, Niopas I, A study on the in-vitro percut aneous absorption of propranolol from disperse systems, J. Pharm. Pharmacol.; 1998, 50, 413-418.

4. Kreilgaard M, Pedersen EJ, Jaroszewski JW, NMR characterization and transdermal drug delivery potential of microemulsion systems, J. Control. Release; 2000, 69, 421-433.

5. Gasco MR, Gallarate M, Pattarino F, In-vitro permeation of azelaic acid from viscosized microemulsions, Int. J. Pharm.; 1991, 69, 193-196.

6. Kriwet K, Müller-Goymann CC, Diclofenac release from phospholipid drug systems and permeation through excised human stratum corneum, Int. J. Pharm.; 1995, 125, 231-242.

7. Trotta M, Influence of phase transformation on indomethacin release from microemulsions, J. Control. Release; 1999, 60, 399-405.

8. Alvarez-Figueroa MJ, Blanco-Méndez J, Transdermal delivery of methotrexate: iontophoretic delivery from hydrogels and passive delivery from microemulsions, Int. J.Pharm.; 2001, 215, 57-65.

9. Pershing LK, Lambert LD, Knut son K, Mechanism of ethanol-enhaced estradiol permeation across human skin in vivo, Pharm. Res.; 1990, 7, 170-175

10. Liu P, Kurihara-Bergstrom T, Good W R, Cotransport of estradiol and ethanol through human skin in vitro: understanding the permeant/enhancer flux relationship, Pharm. Res.; 1991, 8, 938-944.

11. Kim YH, Ghanem AH, Mahmoud H, Higuchi WI, Short chain alkanols as transport enhancers for lipophilic and polar/ionic permeants in hairless mouse skin: mechanism(s) of action, Int. J. Pharm.; 1992, 80, 17-31.

12. Pershing LK, Parry GE, Lambert LD, Disparity of in vitro and in vivo oleic acid-enhanced b-estradiol percutaneous absorption across human skin, Pharm. Res.; 1993, 10, 1745- 1750.

13. T anojo H, Junginger HE, Boddé HE, In-vivo human skin permeability enhancement by oleic acid: transepidermal water loss and Fouriertransform infrared spectroscopy studies, J. Control. Release; 1997, 47, 31-39.

14. Hadgraft J, Skin:the final frontier, Int. J.Pharm.; 2001, 224, 1-18

15. Goldberg-Cettina M, Liu P, Nightingale J, Kurihara-Bergstrom T, Enhanced transdermal delivery of estradiol in vitro using binary vehicles of isopropyl myristate and short-chain alkanols, Int. J. Pharm.; 1995, 1 14, 237-245.

16. Fang JY, Yu SY, Wu PC, Huang YB, Tsai YH, In-vitro skin permeation of estradiol from various proniosome formulations, Int. J. Pharm.; 2001, 215, 91-99.

17. Acharya SP, Moulik SK Sanyal, Mishra BK, Puri PM, Physicochemical Investigations of Microemulsification of Coconut Oil and Water Using Polyoxyethylene 2-Cetyl Ether (Brij 52) and Isopropanol or Ethanol, Journal of Colloid and Interface Science; 2002, 245, 163-170.

18. Attwood D, Mallon C, Taylor CJ, Phase studies of oil-in water phospholipid microemulsions, Int. J. Pharm.; 1992, 84, R5-R8.

19. Aboofazeli R, Lawrence CB, Wicks SR, Lawrence MJ, Investigation into the formation and characterisation of phospholipid microemulsions. III. Pseudo-ternary phase diagrams of systems containing water-lecithin-isopropyl myristate and either an alkanoic acid, amine, alkanediol, polyethylene glycol alkyl ether or alcohol as cosurfactant, Int. J. Pharm.; 1994, 111, 63-72.

20. Aboofazeli R, Lawrence MJ, Investigations into the formation and characterization of phospholipid microemulsions: I Pseudo-ternary phase diagrams of systems containing water-lecithin-alcoholisopropyl myristate, Int. J. Pharm.; 1993, 93, 161-175.

21. Shinoda K, Araki M, Sadaghiani A, Khan A, Lindman B, LecithinBased Microemulsions: Phase Behaviour and Micro-Structure, J. Phys. Chem.; 1991, 95, 989-93.

22. Angelo MD, Fioretto D, Onori G, Palmieri L, Santucvelocity A, Dynamics of water-containing sodium bis(2-ethylhexyl)sulfosuccinate (AOT) reverse micelles: a high- frequency dielectric study, Phys. Rev. E.; 1996, 54, 993-996.

23. Carlfors J, Blute I, Schmidt V, Lidocaine in microemulsion - a dermal delivery system, J. Disp. Sci. Technol.; 1991, 12, 467-482.

24. Israelachvilli JN, Mitchell DJ, Ninham BW, Theory of self assembly of hydrocarbon amphiphiles into micelles and bilayers, J. Chem. Soc. Faraday Trans. II; 1976, 72, 1525-1567.

25. Mitchell DJ, Ninham BW, Micelles, vesicles and microemulsions, J. Chem. Soc. Faraday. Trans. II; 1981, 77, 601 -629.

26. Bhargava HN, Narurkar A, Lieb LM, Using microemulsions for drug delivery, Pharm. Tech.; 1987, 11, 46-52.
27. Attwood, Microemulsions in: J. Kreuter (Ed.), Colloidal Drug Delivery Systems, Dekker, New York; 1994, 31-71.

28. Eccleston J, Microemulsions in: J. Swarbrick, J.C. Boylan (Eds.), Encyclopedia of Pharmaceutical Technology, Marcel Dekker, NewYork; 1994, 9, 375-421.

29. Lawrence MJ, Surfactant systems: microemulsions and vesicles as vehicles for drug delivery, Eur. J. Drug Metab. Pharmacokinet.; 1994, 3, 257-269.

30. Lawrence MJ, Microemulsions as drug delivery vehicles, Curr. Opin Colloid Interface Sci.; 1996, 1, 826-832.

31. Malmsten M, Microemulsions in pharmaceuticals In Handbook of Microemulsion, Science and Technology, Ed: Kumar, P., Mittal, K.L., Marcel Dekker, Inc., New York; 1999, 755- 771.

32. Shaji J, Reddy MS, Microemulsions as drug delivery systems, Pharma Times; 2004, 36 (7), 17-24

33. Sheikh S, Faiyaz S, Sushma T, Farhan JA, Development and bioavilability assessment of ramipril nanoemulsion formulation, Eur. J.Phar. Bio; 2007, 66, 227-243.

34. Shinoda K, Saito H, The effect of temperature on the phase equilibria and the type of dispersion of the ternary system composed of water, Cyclohexane and nonionic surfactant, J. Colloid Interface Sci; 1968, 26, 70-74

35. Walstra P. Emulsion stability, in: P. Becher (Ed.). Encyclopedia of emulsion technology. Marcel Dekke. New York; 1996, P. 1-62.

36. Floury J, Desrumaux. Axelos MAV, Legrand J, Effect of high pressure homogenisation on methylcellulose as food emulsifier, J. Food. Engg, $2003 ; 58,227-238$

37. Pavankumar VK, Nanoemulasions, Pharmainfo net; 2008

38. Lawrence MJ, Rees GD, Microemulsion-based media as novel drug delivery systems. Adv. Drug. Deliv. Rev; 2000, 45, 89-121.

39. Devarajan V, Ravichandran, Nanoemulsion as modified drug delivery tool, Int. J. Comprehensive pharmacy; 2011.

40. Pout on CW, Self-emulsifying drug delivery system, assessment of the efficiency emulsification, Int. J. Pharm; 1985, 27, 335-48

41. Shafiq S, Shakeel F, Talegaonkar S, Ahmed FJ, Khar RK, Mushir A Development and bioavailability assessment of ramipril nanoemulsion formulation, Eur. J. Pharm. Biopharm; 2007, 66, 227 43.

42. Tadros TF, Becher P, (Ed.), Encyclopedia of emulsion technology, 1, Marcel Dekker, New York; 1983, 129-285.

43. Shaji J, Joshi V, Self-microemulsifying drug delivery system (SMEDDS) for improving bioavailability of hydrophobic drugs and its potential to give sustained release dosage forms, Indian J. Pharm. Educ; 2005, 39(3), 130-5.

44. Nakajima H, Industrial Applications of Microemulsions, Marcel Dekker, New York; 1997.

45. Benita S, Levy MY, J.Pharm. Sci; $1993,82,1069$.

46. Sing AJF, Gracia A, Lachaise J, Brochette P, Salager JL, Colloi Surf.; 1999, 152, 31.

47. Solans C, Esquena J, Forgiarini AM, Ulson N, Morales D, Izquierdo P, Azemar N, Garcia-Celma MJ, Absorption and Aggregation of Surfactants in Solution, Marcel Dekker, New York; 2003, 109.

48. Mason TG, Krall AH, Gang H, Bibette J, Weitz DA, in Encyclopedia of Emulsion Technology, edited by P. Becher sMarcel Dekker, New York; 1996d, 4, 299

49. Gupta PK, Pandit JK, Kumar A, Swaroop P, Gupta S, The Pharma Research (T.Ph. Res.); 2010, 3, 117-138.

50. Date AA, Nagarsenker S, Parenteral microemulsion: An overview, Int J. Pharm; 2008, 355, 19-30.

51. Thompson W, Kelvin L, On the equilibrium of vapour at a curved surface of liquid, Phil. Mag; 1871, 442-448.

52. Morales D, Gutierrez JM, Garcú'a-Celma MJ, Solans YC, A study of the relation between bicontinuous microemulsion and $\mathrm{O} / \mathrm{W}$ nanoemulsion formulation, Langmuir; 2003, 19, 7196-7200.

53. Miyazaki S, Suzuki S, Kawasaki N, Endo K, Takahashi A, Attwood D. In situ gelling glucan formulations for sustained release ocular delivery of pilocarpine hydrochloride, Int JPharm; 2001, 229, 29-36.

54. Wu C, Qi H, Chen W, Huang C, Su C, Li W, Hou S, Preparation and evaluation of a carbopol/HPMC-based in situ gelling ophthalmic system for puerarin, Yakugaku Zasshi; 2007, 127,183-91.

55. Khan KA, Rhodes CT, Effect of compaction pressure on the dissolution efficiency of some direct compression systems, Pharm Acta Helv; 1972, 47, 594-607.

56. Tamilvanan S, Submicron emulsions as a carrier for topical (ocular and percutaneous) andS nasal drug delivery, Indian J. Pharm. Educ; 2004, 38(2), 73-78. 
